\title{
Turbine blades production technique equipment built with a glance of high-gradient directional crystallization process nature
}

\author{
Alexander Echin and Yury Bondarenko \\ FSUE “All Russian Scientific Research Institute of Aviation Materials” (VIAM), 105005, Radio str. 17, Moscow, Russia
}

\begin{abstract}
The influence of the high-gradient directional crystallization on the structural components (the interdendritic distance and porosity) of the superalloys is presented in the Article. The industrial-scale highgradient plant of UVNS-6 type and some benefits of its use are shown here as well. Some test specimens manufactured on the UVNS-6 are studied with measurement of the interdendritic distance. The temperature gradient is estimated by experimental method.
\end{abstract}

\section{Introduction}

Nowadays the single-crystal turbine rotor blades are manufactured with the help of the small temperature gradient technique on the UVNK-type furnaces. Therefore, the liquid-solid area at the crystallization front is about ten millimeters high. The liquid melt flow is restricted because of the dendritic channels overlapping by twofold axis. Owing to the molar volumes difference of liquid and solid phases in the course of crystallization some dendritic porosity are generated in the dendrites base [1]. Therefore, dendritic structure with considerable dendritic segregation and interdendritic porosity is created in the casting $[2,3]$. Temperature gradient growth provides some liquid-solid zone height decrease at the crystallization front. Temperature gradient growth facilitates the dendrites bases replenishment and, therefore, promotes reduction of the size and quantity of the interdendritic porosity [1].

The process of the high-gradient directional crystallization was developed in the Federal State Unitary Enterprise "All Russian Scientific Research Institute of Aviation Materials" (VIAM) for ensuring the structure pattern homogeneity, limiting dendritic segregation and porosity volume decrease. Since 1974 some specialized vacuum melting plants of the directional crystallization with different cooling systems have been designed and manufactured, for example UVNES-1, UVNES-2, and UVNES-3. The furnace design and furnace size were similar. The furnace designed for crystallization of the block of several test specimen or one-two blades (with length of $\sim 150-200 \mathrm{~mm}$ ). The temperature profile data along the mold-heating furnace, gathered with the thermocouples installed on the surface of the ceramic molds, allowed estimating the temperature gradient and the growth front repositioning in the course of the directional crystallization [1]. The analysis of the findings has shown that the directional crystallization in the ceramic mold on the copper water-cooled crystallizer (Bridgman's method) provides relatively low gradients at the crystallization front of $G=30-40^{\circ} \mathrm{C} / \mathrm{cm}$ because of insufficient removal of the crystallization heat by radiation from the surface of the mold. The use of water-cooled ring screens in the lower part of the mold-heating furnace (UVNES-2 plant) has provided some increase in values of the temperature gradient up to $G=50-60^{\circ} \mathrm{C} / \mathrm{cm}$. The use of liquid-metal coolant cooler (tin bath) in the UVNES-3 plant (called Liquid Metal Cooling (LMC) method) has provided the temperature gradient up to $G=80^{\circ} \mathrm{C} / \mathrm{cm}$. Further development of the furnace design with liquid-metal coolant cooler is the following. There applied two-zonal heater, heat shields, and increase of working temperature in the mold-heating furnace (up to $1700^{\circ} \mathrm{C}$ ) at he expense of use of more fire-proof ceramic molds consisting entirely of aluminum oxide $\left(99,6\right.$ weight $\%$ of $\left.\mathrm{Al}_{2} \mathrm{O}_{3}\right)$ and without any siliceous refractory, has provided the temperature gradient growth up to $G=200-250{ }^{\circ} \mathrm{C} / \mathrm{cm}[1]$.

Based on the investigation results there have been enunciated and experimentally verified some basic requirements for the high gradient technique of GTE(gas turbine engine) blades molding:

- application of the directional crystallization method with liquid-metal coolant cooler, the use of liquid-metal coolant cooler with lower melting temperature;

- increase of working temperature in heating furnaces, distance reduction between heater and surface of liquid-metal coolant cooler;

- application of effective heat shields between zone of heating and the cooling zone and

- increase of heat conductivity of ceramic molds.

Relying on the mentioned above concept, there has been constructed the laboratory vacuum high-gradient UVNS-4 melting plant. There has been studied the nature of the high gradient technique in terms of the interdendritic distance, porosity and factor of segregation in high-temperatureresistant nickel-based alloys. 


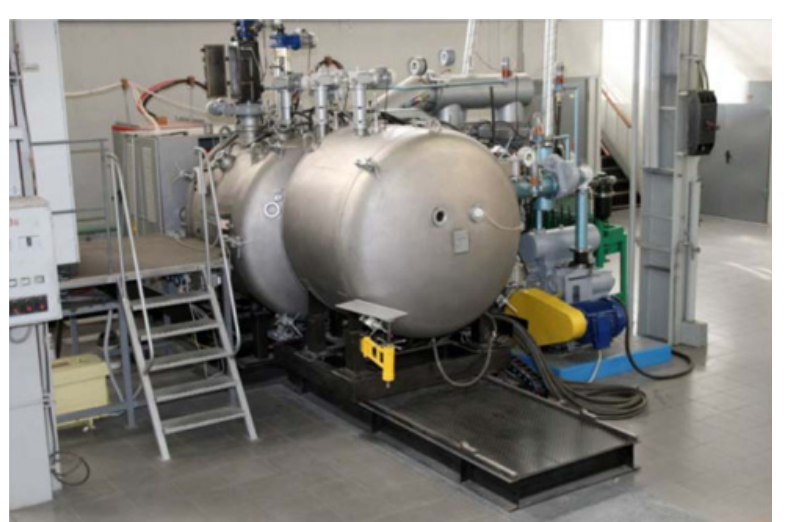

Figure 1. Industrial-scale high-gradient plant with the sluice chamber UVNS-6.

The purpose of the present work is to estimate the temperature gradient of the industrial-scale plant UVNS-6.

\section{Experimental procedure}

The influence of the temperature gradient on the dendrite arm spacing, porosity and segregation was investigated on the test specimen manufactured with the help of the Liquid Metal Cooling (LMC) method on the UVNS-4 plant. Tin bath was used there as the liquid-metal coolant cooler. Full details of the casting unit (e.g. design and specification) have been previously reported $[1,4]$. There have been manufactured cylindrical single-crystal test specimen of $15 \mathrm{~mm}$ in diameter from moldings of the VZhM 1 (with 9.0 wt.\% Re) superalloy of the third generation [5]. The crystallisation was carried out at the same crystallization rate of $5 \mathrm{~mm} / \mathrm{min}$, but with different temperature gradient at the front growth.

The temperature gradient was estimated on the industrial-scale high-gradient UVNS-6 plant of semicontinuous action. The view of the plant is shown on Fig. 1. The plant equipped with the suspension unit with two mold blocks and the sluice chamber. It allows increasing the plant performance. The plant is equipped with the sliding heat shields which separate heating zone from the cooling one (tin is liquid-metal coolant cooler here). The use of the shields allows getting sufficient thermal gradient through heating-cooling zone [6]. The plant is equipped with main process-dependent parameters control system based on the industrial computer. Specifications are shown in the Table 1.

It is known that one of the main structural features is the primary dendritic axes distance ( $\lambda$, micron). The distance depends on the melt cooling rate according to the following relation:

$$
\lambda=\mathrm{a}(\mathrm{GR})^{-0.22},
$$

where

a - crystallization range dependant factor;

$\mathrm{G}$ - temperature gradient $\left({ }^{0} \mathrm{C}\right)$

$\mathrm{R}$ - crystallization rate ( $\mathrm{mm} / \mathrm{min}$.) [7].

According to the relation we have the more temperature gradient, the less interdendritic distance.
Table 1. UVNS-6 plant specification.

\begin{tabular}{|l|l|}
\hline Power consumption, $\mathrm{kW}$ & 200 \\
\hline $\begin{array}{l}\text { Working environment: vacuum, } \mathrm{Pa} \\
\mathrm{mm} \mathrm{Hg}\end{array}$ & $6,65 \bullet$ \\
& $10^{-1}$ \\
& $5 \bullet 10^{-3}$ \\
\hline Crucible capacity, $\mathrm{kg}$ & 15 \\
\hline Metal temperature in the crucible, ${ }^{\circ} \mathrm{C}$ & 1700 \\
\hline Temperature in the mold-heating furnace, ${ }^{\circ} \mathrm{C}$ & 1700 \\
\hline Sink rate, $\mathrm{mm} / \mathrm{min}^{-}$ & $1-10$ \\
\hline Mold-heating furnace laboratory, mm & $140 \times$ \\
& $360 \times 400$ \\
\hline Temperature gradient, max ${ }^{\circ} \mathrm{C} / \mathrm{cm}$ & $150-200$ \\
\hline Crystallizer tin bath capacity, $\mathrm{kg}$ & 150 \\
\hline $\begin{array}{l}\text { Temperature of the liquid-metal coolant } \\
\text { cooler, }{ }^{\circ} \mathrm{C}\end{array}$ & 300 \\
\hline Performance, molds/process by cycle & 2 \\
\hline Working site space, $\mathrm{m}^{2}$ & 30 \\
\hline
\end{tabular}

There was measured the interdendritic distance of the specimen manufactured on the UVNS-6 plant for their structure quality estimation. Experimental casting was carried out in the ceramic molds using the precision casting manufacturing technology. The molds were made of the mixture of electrocorundum and $\mathrm{SiO}_{2}$ binding First there were carried out gas evacuation from the furnace, then mold-heating furnace temperature increased up to $1580^{\circ}$, batch of the VZhM-1 superalloy melted in the melting induction crucible, and filled in the ceramic mold. Then the ceramic mold with the melt sinks from the moldheating furnace to the liquid-metal coolant cooler bath. The crystallization rate maintained constant at the level of $\mathrm{R}_{\text {crist }}=5 \mathrm{~mm} / \mathrm{min}$. The liquid-metal coolant cooler temperature was about $300^{\circ} \mathrm{C}$.

When the solidification process was over, the ceramic mold material removed and castings were macro-etched to reveal grain structure and surface casting defects. It was used a macro metallographic etchant consisting of $\mathrm{HCl}$ and $\mathrm{H}_{2} \mathrm{O}_{2}$.

Then there have been chosen some test specimen for metallographic examination according to the procedure shown in Fig. 2. The test specimen number 1 corresponds to the lower part of the casting. The test specimen number 2 - to the casting midsection. The test specimen number 3 - to the casting upper part.

There have been manufactured six-fingered ceramic molds using the precision casting manufacturing technology for the purpose of the UVNS-6 plant temperature gradient characteristic estimation in the process of the directional crystallization. The molds were made of electrocorundum and the $\mathrm{SiO}_{2}$ binding.

There have been used three tungsten-rhenium thermocouples of the VR 5/20 type (thermocouples layout showed by cross-marks on the Figure below). The thermocouples were fixed on the mold surface in its middle part with a pace of $\sim 10 \mathrm{~mm}$ from each other (see Fig. 2). The thermocouples were inserted in the ceramic pipe-tube made of aluminum oxide for heat and electric protection.

The thermocouples were fixed on the surface of the molds by electrocorundum and $\mathrm{SiO}_{2}$ mixture. After alloy 
Table 2. Segregation factor-directional crystallization conditions dependence of the nickel-based heat-resistant alloys Rene N5 and VZhM-1.

\begin{tabular}{|l|l|l|l|l|l|l|l|l|}
\hline \multirow{2}{*}{ Alloy } & \multirow{2}{*}{$\mathrm{G},{ }^{\circ} \mathrm{C} / \mathrm{cm}$} & \multicolumn{2}{|l|}{$\mathrm{k}=\left(\mathrm{c}_{\mathrm{dc}} / \mathrm{c}_{\mathrm{id}}\right)^{*}$} \\
\cline { 3 - 9 } & & $\mathrm{Al}$ & $\mathrm{Cr}$ & $\mathrm{Mo}$ & $\mathrm{W}$ & $\mathrm{Ta}$ & $\mathrm{Co}$ & $\mathrm{Re}$ \\
\hline \multirow{2}{*}{ Rene N5 } & 60 & 0,7 & 0,8 & 0,7 & 2,0 & 0,7 & 1,1 & 2,5 \\
\cline { 2 - 9 } & 200 & 0,9 & 0,9 & 0,8 & 1,4 & 0,8 & 1,2 & 1,5 \\
\hline \multirow{2}{*}{ VZHM-1 } & 60 & 0,7 & 1,2 & 1,2 & 2,1 & 0,5 & 1,2 & 3,4 \\
\cline { 2 - 10 } & 200 & 0,8 & 1,0 & 0,9 & 1,5 & 0,6 & 1,1 & 2,5 \\
\hline
\end{tabular}

* Where

$\mathrm{c}_{\mathrm{dc}}-$ Element concentration in the dendrite core;

$c_{i d}-$ Element concentration in the interdendritic region.

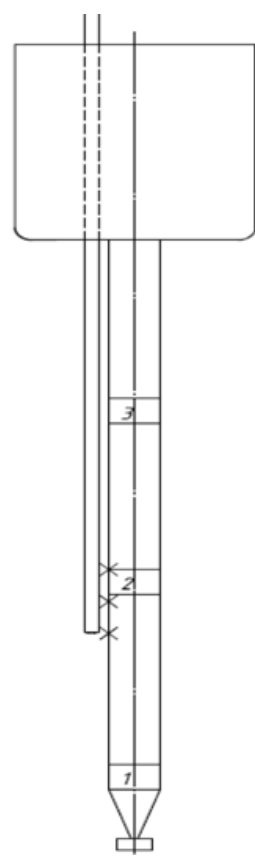

Figure 2. The thermocouples layout on the ceramic mold and the test specimen sampling method.

Table 3. Interdendritic distance (PDAS) in test specimen number 1,2 , and 3 .

\begin{tabular}{|l|l|l|l|}
\hline $\begin{array}{l}\text { Order } \\
\text { Number }\end{array}$ & $\begin{array}{l}\text { Sampling } \\
\text { place }\end{array}$ & $\begin{array}{l}\text { Tests } \\
\text { number, N }\end{array}$ & $\begin{array}{l}\text { PDAS, } \\
\text { micron }\end{array}$ \\
\hline 1 & bottom & 117 & $215,2 \pm 3,0$ \\
\hline 2 & middle & 144 & $210,7 \pm 3,1$ \\
\hline 3 & top & 73 & $203,6 \pm 4,0$ \\
\hline
\end{tabular}

melting, the directional crystallization process was carried out with rate of $\mathrm{R}=5 \mathrm{~mm} / \mathrm{min}$. At the same time, the mold with thermocouples goes down from heating zone to cooling one. The thermocouples signal was registered and recorded by the industrial computer.

The dendrite distance estimation was carried out with the help of etched test specimen 1,2,3. The distance between the primary dendrite arm centers, measured along the crystallographic direction $\langle 001\rangle$ was regarded as the dendrite distance (Primary Dendrite Arm Spacing or PDAS). The field for PDAS quantitative analysis on the microsection was chosen so that the dendrite axes of the

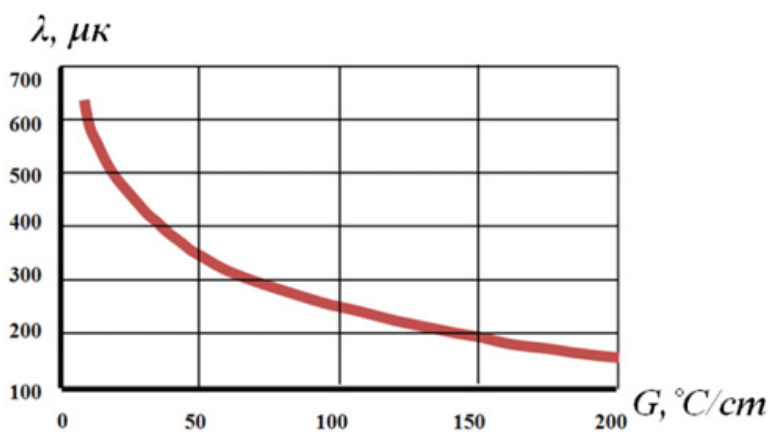

Figure 3. Influence of temperature gradient on dendrite arm spacing.

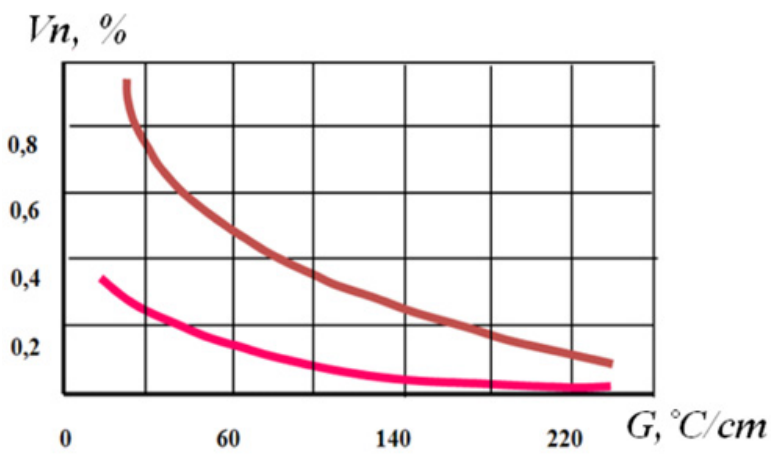

Figure 4. Influence of temperature gradient on porosity (volume fraction) characteristic (the upper curve - test specimen after heat treatment, lower one - in cast condition).

primary were located at the same pace (Fig. 5). The results are shown in Table 3. Volume fraction of porosity was determined by a quantitative method for the entire area of the sample cross-section.

\section{Results}

\subsection{The temperature gradient influence on the interdendritic distance, porosity and segregation in superalloys}

The temperature gradient-interdendritic distance (and porosity) characteristics found experimentally on the UVNS-4 plant, see Figs. 3 and 4.

As can be seen from Fig. 4 pore volume after heat treatment is increased due to dissolution of the $\gamma / \gamma$, eutectics. 


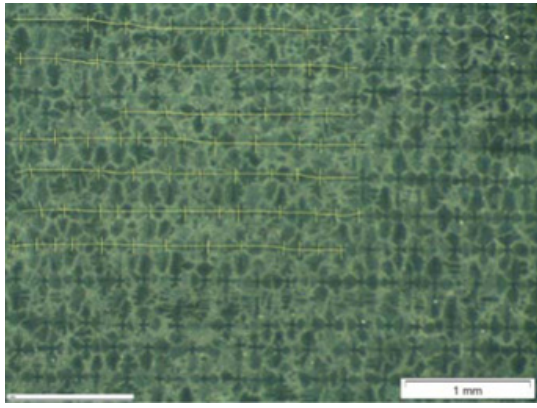

No. 1

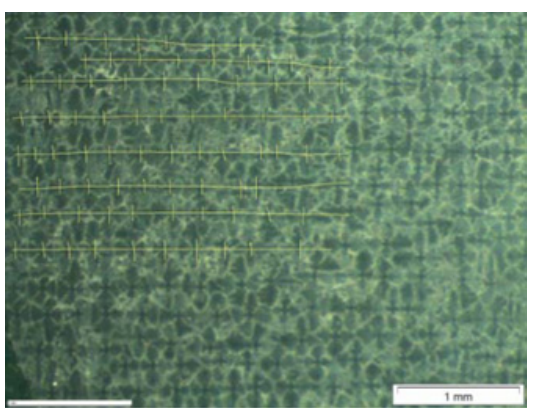

No. 2

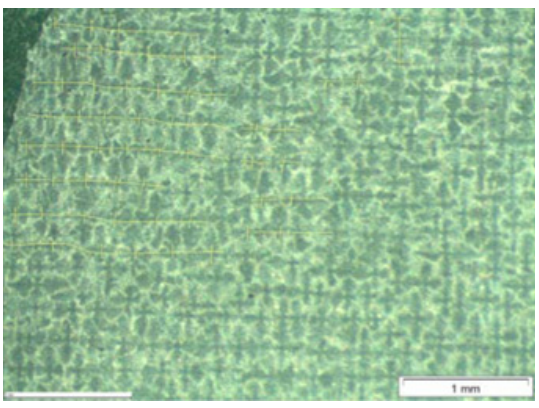

No. 3

Figure 5. Dendritic cellular pattern in different fields of the metallographic samples No. 1, No. 2, and No. 3 at 25 magnifying power with the dendrites drawn, for interdendritic distance measurement.

It is obvious that the elements like $\mathrm{Al}$, Ta enrich in interdendritic regions, whereas the elements $\mathrm{W}, \mathrm{Re}$ - concentrate in the dendritic regions. It is necessary to note that the chemical inhomogeneity influenced by the distance of the dendrite. There is rather simple dependance. The higher the temperature gradient - the better the chemical homogeneity. In the monocrystals manufactured by the high-gradient directed crystallization method (UVNS-4 plant), the Re segregation factor is about $30 \%$ lower, than the segregation factor in the monocrystals manufactured by the method of the conventional directional crystallization (UVNK-9). This fact is the matter of the most importance especially for state-of-the-art heat-resistant alloys (with $\mathrm{W}$ and Re), where even rather long high-temperature homogenization does not eliminate chemical inhomogeneity [8].

\subsection{Microstructure}

It is shown by the metallographic examination of test specimen Nos. 1, 2, 3 that after the directional

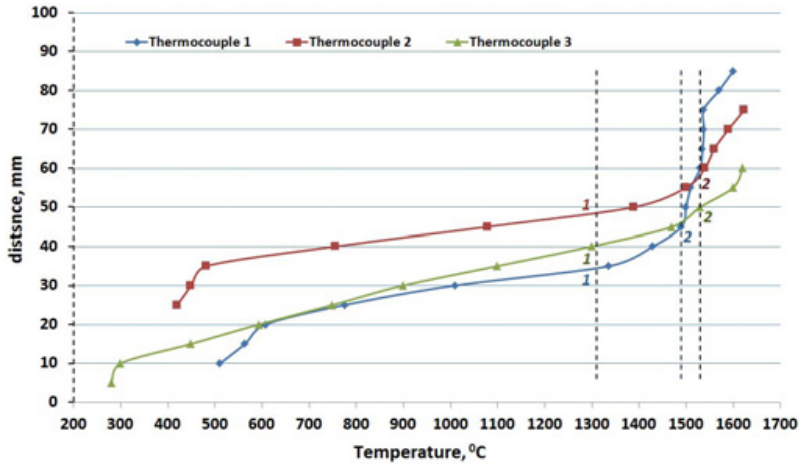

Figure 6. Temperature-furnace height distributions curve.

crystallization on the UVNS-6 plant there shaped finedispersed dendritic pattern with interdendritic distance $(\lambda)$ of $\sim 210$ microns along the full length of the casting.

\subsection{The temperature gradient estimation}

Temperature-furnace height distributions curve based on the thermocouples data shown on the Fig. 6. The given curves are specific for the experiments carried out on the UVNS-type plants because of the liquid-metal coolant cooler bath.

There has been chosen the point No. 1 corresponding to the alloy temperature solidus for estimation of the temperature gradient by the curves. Then there has been chosen another point No. 2 for definition the temperature about $1 \mathrm{~cm}$ above temperature solidus of the alloy. The temperature difference between point 2 and temperature solidus of the alloy gives us the value of the temperature gradient at the front growth. The temperature gradient $(\mathrm{G})$ for the UVNS-6 plant is approximately $180-200{ }^{\circ} \mathrm{C} / \mathrm{cm}$.

\section{Summary}

The high-gradient technology of the directional crystallization provides more homogeneous pattern structure with the smallest interdendritic distance and the minor porosity volume fraction.

The UVNS-6 plant allows providing high values of the temperature gradient that leads to manufactured products structure quality improvement. The castings manufactured on UVNS-6 plant have fine-dispersed dendritic pattern with interdendritic distance $(\lambda) \sim 210$ microns.

\section{References}

[1] E. Kablov Cast blades of gas turbine engines: alloys, technologies, coatings $2^{\text {nd }}$ ed. (2006)

[2] Yu. Bondarenko, A. Echin, V. Surova, A. Narsky Liteynoye proizvodstvo 5, 36-39 (2011) 
[3] V. Gerasimov, E. Visik, E. Kolyadov Liteynoye proizvodstvo. 3, 21-23 (2013)

[4] E. Kablov, Yu. Bondarenko, V. Surova Foundry heatresistant alloys. Kishkin's effect: science and research compilation, 194-205 (2006)

[5] E. Kablov, N. Petrushin, V. Sidorov, I. Demonis Foundry heat-resistant alloys. Kishkin's effect: science and research compilation, 79-97 (2006)
[6] E. Kablov, Yu. Bondarenko, A. Echin, V. Surova Aviation materials and technologies 1, 3-7 (2012)

[7] R. Shalin, I. Svetlov, E. Kachanov, etc. Monocrystals of the nickel heat-resistant alloys (1997)

[8] N. Petrushin, M. Bronfin, E. Kablov, I. Hatsinskaya, E. Chabina, I. Roschin, O. Timofeeva Foundry heat-resistant alloys.0 Kishkin's effect: science and research compilation, 142-154 (2006) 